\title{
HEALTH WORKERS IN THE CASE MANAGEMENT OF TUBERCULOSIS AND DIABETES MELLITUS AT TYPE B HOSPITAL, YOGYAKARTA
}

\author{
Zulkarnain, Iman Permana, Merita Arini \\ Masters Program in Hospital Management, Universitas \\ Muhammadiyah Yogyakarta
}

\begin{abstract}
Background: Developing countries shoulder most of the burden of diabetes and tuberculosis as these diseases often coexist in those countries. Successful cotreatment management of tuberculosis (TB) and diabetes mellitus (DM) is the responsibility of the medical providers and health care workers. Public health workers in TB-DM programs and other facilities play an important role in helping patients complete their TB and DM treatment. This study aimed to assess the awareness, acceptance and collaboration of the health workers in the case management of TB-DM at type B Hospital, Yogyakarta.

Subjects and Method: This was a qualitative case study. A sample of 5 health workers and 3 patients was selected for this study. The themes under-study were awareness, acceptance, and collaboration of health workers in case management of TB-DM. The data were collected by interviews, observation and document review. The data were analyzed in 3 steps: data reduction, data presentation, and conclusion/ verification.

Results: The main themes in this study included: 1) Integrated TB-DM management awareness; 2) Willingness and readiness to collaborate TB-DM; 3) Implementation of TB-DM program; 4) Collaboration of TB-DM programs with internal and external parties. The existing obstacles were that there was no strong policy from the government, lack of awareness among health workers and patients, and no reporting cases of TB-DM had been done. Supporting factors such as, utilities and monitoring were good both internally and externally.

Conclusion: The collaboration of Tuberculosis and Diabetes Mellitus in type B Hospital, Yogyakarta has not been fully implemented. There is a need to improve collaboration between health workers, related agencies, and private organizations. Awareness and acceptance about TB-DM needs to be improved
\end{abstract}

Keywords: awareness, acceptance, collaboration, tuberculosis, diabetes mellitus

\section{Correspondence:}

Zulkarnain. Masters Program in Hospital Management, Universitas Muhammadiyah Yogyakarta, Jl. Brawijaya, Kasihan, Bantul, Yogyakarta.

Email: zulkarnain_sjamsuri@rocketmail.com. Mobile: 082138702144. 